\title{
Holographic 3DTV Research within the European 3DTV Project
}

\author{
Levent Onural \\ Dept. of Electrical and Electronics Eng., Bilkent University, TR-06800 Ankara, Turkey \\ onural@bilkent.edu.tr
}

\begin{abstract}
A European project on 3DTV has been functional since September 2004. Holographic displays for 3DTV and signal processing issues associated with diffraction and holography are among research interests. The research has already generated interesting results.

(C) 2008 Optical Society of America

OCIS codes: (090.2870) Holographic Displays; (090.5694) Real-time Holography; (070.0070) Fourier Optics and Signal Processing; (090.1995) Digital Holography
\end{abstract}

\section{Introduction}

A European project, with the acronym 3DTV has been operational since September 2004 with about 180 contributing researchers from 19 institutions in seven countries. The project covers all functional blocks of an end-to-end 3DTV system including capture, representation, compression, transport and display of 3D video data. Furthermore, competing technologies for all these functional blocks are being investigated in a comparative manner. Researchers are grouped under five technical committees (TC). One of these TCs is focusing on display issues in 3DTV, whereas another TC is investigating signal processing issues in diffraction and holography $[1,2,3,4]$.

Among the candidate technologies for 3DTV, autostereoscopic displays for multi-view video is going to be the dominating choice during the next few years. Limited light field rendering displays, where pixels can generate light rays with controllable intensity and direction within some limits, are also gaining momentum. However, the ultimate goal is to record, and then reconstruct, space filling light with all of its physical properties. We group all such light reproduction techniques, under "holographic displays" and thus expand the coverage of the term beyond classical interference recording based holography. A survey of current techniques for 3DTV displays can be found in [5]. It is envisioned that future 3DTV systems will have decoupled input and display units, thus the capture unit will try to get as complete as possible 3D scene data without considering how it is displayed later on, whereas the display unit should be able to render from a generic 3D video data presented to it [6].

An outline of the ongoing research within the 3DTV Project, together with some intermediate results are presented in the next sections.

\section{Holographic 3DTV Display Research within 3DTV Project}

Current holographic 3DTV display research within the 3DTV Project is based primarily on different forms of spatial light modulators driven mostly by computer generated holographic video signals. There are also activities on developing novel dynamic holographic display materials [7]. Furthermore, VLSI technologies are being investigated for the purpose of designing and implementing more appropriate display arrays for holographic 3DTV display purposes. Integral imaging techniques are also among the interests.

For example, liquid crystal (LC) and liquid crystal on silicon (LCoS) commercial SLMs are used for testing of optical reconstructions from computer generated holographic signals $[8,9]$. Furthermore, commercially available deflectable micromirror devices (DMAD) are also investigated for their suitability and limitations as core holographic display elements.

There is no doubt that currently available SLMs are far from being satisfactory as holographic displays due to their size and geometry limitations [8, 9]. However, there are strong expectations that the parameters will develop, and therefore, in a decade or so, dynamic 3D holographic displays based on SLMs are expected to yield satisfactory results.

One way to overcome the limitations of current SLMs is to use an array of SLMs driven in parallel to yield higher resolution 3D displays. Different geometries for such arrays are among current research topics. 


\section{Signal Processing Techniques in Diffraction and Holography}

One of the major line of research within the 3DTV Project is the investigation of novel signal processing techniques related to diffraction and holography, and their applications to holographic 3DTV displays [10, 11, 12, 13]. It is concluded that such novel signal processing techniques are under-utilized in this field; one reason for this could be the intrinsic complicatedness of such signals. Even the effects of even basic operations like the sampling of diffraction signals, which is absolutely necessary for subsequent digital signal processing, are rather recently understood $[14,15]$. Applications of wavelets, and related novel basis functions like beamlets, ridgelets, fresnelets, etc., to process or efficiently generate holographic signals are promising $[16,10]$.

A major activity is related to computation of the diffraction field due to a given abstract 3D scene description. Furthermore, computation of driving signals associated with a given display device, by considering all its physical restrictions is another major activity $[10,11]$.

Fast methods to compute diffraction due to a given 3D abstract scene, and to compute driving signals for specific physical display devices to generate desired diffraction signals in space are of prime interest. Methods using fast commercial graphical processing units (GPUs) of current computers are being developed [17, 18].

Recovery of phase information from intensity measurements and different forms of profilometric methods are also among the research interests [19].

\section{References}

1. L. Onural, T. Sikora, and A. Smolic. An overview of a new european consortium: Integrated three-dimensional television - capture, transmission and display (3DTV). In Proc. of European Workshop on the Integration of Knowledge, Semantics and Digital Media Technology (EWIMT), Nov 2004

2. L. Onural, T. Sikora, J. Ostermann, A. Smolic, M. R. Civanlar, and J. Watson. An assessment of 3DTV technologies. In Proc. of NAB Broadcast Engineering Conference 2006, pages 456-467, Apr 2006.

3. L. Onural and H. M. Ozaktas. Three-dimensional television: from science-fi ction to reality. In H. M. Ozaktas and L. Onural, editors, ThreeDimensional Television: Capture, Transmission, Display. Springer, 2008.

4. M. R. Civanlar, J. Ostermann, H. M. Ozaktas, A. Smolic, and J. Watson. Special issue on three-dimensional video and television. Signal Processing: Image Communication, 22(2):103-107, Feb 2007.

5. P. Benzie, J. Watson, P. Surman, I. Rakkolainen, K. Hopf, H. Urey, V. Sainov, and C. von Kopylow. A survey of 3DTV displays: Techniques and technologies. IEEE Tr. on Circuits and Systems for Video Technology. In Print.

6. L. Onural. Television in 3D: What are the prospects? Proceedings of the IEEE, 95(6):1143-1145, Jun 2007.

7. K. Beev, K. Beeva, and S. Sainov. Materials for holographic 3DTV display applications. In H. M. Ozaktas and L. Onural, editors, ThreeDimensional Television: Capture, Transmission, Display. Springer, 2008.

8. M. Kovachev, R. Ilieva, L. Onural, G. B. Esmer, T. Reyhan, P. Benzie, J. Watson, and E. Mitev. Reconstruction of computer generated holograms by spatial light modulators. In Lecture Notes in Computer Science - Multimedia Content Representation, Classification and Security, volume 4105/2006, 2006.

9. M. Kovachev, R. Ilieva, P. Benzie, G. B. Esmer, L. Onural, J. Watson, and T. Reyhan. Holographic displays using spatial light modulators. In H. M. Ozaktas and L. Onural, editors, Three-Dimensional Television: Capture, Transmission, Display. Springer, 2008.

10. L. Onural, A. Gotchev, H. M. Ozaktas, and E. Stoykova. A survey of signal processing problems and tools in holographic three-dimensional television. IEEE Tr. on Circuits and Systems for Video Technology. In Print.

11. L. Onural and H. M. Ozaktas. Signal processing issues in diffraction and holographic 3DTV. In EURASIP 13th European Signal Processing Conference (EUSIPCO 2005) (CD-ROM), Sep 2005.

12. L. Onural and H. M. Ozaktas. Signal processing issues in diffraction and holographic 3DTV. Signal Processing: Image Communication, 22(2):169-177, Feb 2007.

13. T. Kreis. Digital holography methods in 3D-TV. In Proc. of 3DTV-CON 2007, May 2007.

14. L. Onural. Sampling of the diffraction fi eld. Appl Opt, 39(32):5929-5935, 2000.

15. L. Onural. Exact analysis of the effects of sampling the scalar diffraction fi eld. Journal of the Optical Society of America A, 24(2):359-367, 2007.

16. A. Gotchev and L. Onural. A survey on sampling and quantization in diffraction and holography. In Workshop on Spectral Methods and Multirate Signal Processing, SMMSP 2006, volume TICSP Series 34, pages 179-190, Sep 2006.

17. I. Hanák, M. Janda, and V. Skala. Full-parallax hologram synthesis of triangular meshes using a graphical processing unit. In Proc. of 3DTV-CON 2007, May 2007.

18. L. Ahrenberg, P. Benzie, M. Magnor, and J. Watson. Computer generated holography using parallel commodity graphics hardware. Optics Express, 14(17):7636-7641, Aug 2006.

19. E. Stoykova, J. Harizanova, and V. Sainov. Pattern projection profi lometry for 3D coordinates measurement of dynamic scenes. In H. M. Ozaktas and L. Onural, editors, Three-Dimensional Television: Capture, Transmission, Display. Springer, 2008. 